\title{
Therapeutic strategies for head and neck cancer based on p53 status (Review)
}

\author{
ICHIRO OTA $^{1}$, NORITOMO OKAMOTO ${ }^{1}$, KATSUNARI YANE ${ }^{2}$, AKIHISA TAKAHASHI ${ }^{3}$, \\ TAKASHI MASUI ${ }^{1}$, HIROSHI HOSOI ${ }^{1}$ and TAKEO OHNISHI ${ }^{4}$ \\ ${ }^{1}$ Department of Otolaryngology-Head and Neck Surgery, Nara Medical University, Kashihara, Nara 634-8522; \\ ${ }^{2}$ Department of Otolaryngology, Nara Hospital, Kinki University School of Medicine, Ikoma, Nara 630-0293; \\ ${ }^{3}$ Advanced Scientific Research Leaders Development Unit, Gunma University, Maebashi, Gunma 371-8511; \\ ${ }^{4}$ Department of Radiation Oncology, Nara Medical University, Kashihara, Nara 634-8522, Japan
}

Received October 31, 2011; Accepted December 19, 2011

DOI: $10.3892 /$ etm.2012.474

\begin{abstract}
Squamous cell carcinomas of the head and neck (HNSCC) are one of the most common types of cancers worldwide, and despite advances in treatment, they still represent a clinical challenge. Inactivation of one or more components in the p53 signaling pathway is an extremely common event in human neoplasia, including HNSCC. The loss of p53 function is responsible for increased aggressiveness in cancers, while tumor chemoresistance and radioresistance can depend on deleted p53 expression, or on the expression of mutated-p53 proteins. Thus, consideration and manipulation of the $p 53$ status during HNSCC cancer therapy should be considered. This review discusses the $p 53$ signaling pathways activated by various cellular stresses, including exposure to cancer therapies. The recognition of the $p 53$ status in cancer cells is a significant factor and could provide valuable assistance during the selection of an effective therapeutic approach.
\end{abstract}

\section{Contents}

1. Introduction

2. The $p 53$ signaling pathway is activated by various cellular stresses

3. $p 53$-dependent cancer therapy via the restoration of $\mathrm{p} 53$ function

4. p53-independent cancer therapy

5. Conclusion

Correspondence to: Dr Ichiro Ota, Department of Otolaryngology-Head and Neck Surgery, Nara Medical University, 840 Shijo-Cho, Kashihara, Nara 634-8522, Japan

E-mail: iota@naramed-u.ac.jp

Key words: head and neck cancer, $p 53$, chaperone, therapy

\section{Introduction}

HNSCC is the sixth most common type of cancer worldwide. More than 49,000 new cases of HNSCC cancer are predicted to have occurred in the US in 2010 (1). The disease is multifactorial in its pathogenesis and is associated with smoking, alcohol and infection with the human papillomavirus (HPV) (2). However, the abrogation of p53 function is one of the most common molecular alterations in human cancer cells, including HNSCC (3-5). The prognosis for patients with tumors bearing p53 mutations is often worse than for those with tumors lacking a wild-type $p 53$ (wtp53) gene (6). For predictive assays, which can be used to evaluate prognosis in cancer therapy, the genetic status of the p53 gene is one of the most critical candidates among various cancer-related genes (7). In addition, the spectrum of p53 deletions or mutations observed among tumor cells suggests that the mutations vary in their prognostic power. Disruptive p53 mutations in tumor DNA are reported to be associated with reduced survival following surgical treatment of HNSCC (2).

It has been previously reported that the radio-, heat- and chemo-sensitivities of HNSCC cells are $p 53$-dependent, and are closely correlated with induction of apoptosis in vitro (8-10) and in vivo (11-13). Consequently, the restoration of wt $p 53$ function and $p 53$-independent therapy have been developed as therapeutic strategies to target tumors with abrogated wtp53 functions.

In this review, cancer therapies aimed at targeting signaling pathways controlled by p53 are described. These include p53-gene therapy, chemical chaperones, p53 C-terminal peptides and small molecules that can target $\mathrm{p} 53$. In addition, therapeutic strategies independent of p53 status in cancer cells are discussed. These include high-linear energy transfer (LET) heavy-ion radiation, and enhancement of cancer therapies with other strategies, including an RNA-silencing therapy targeted at DNA repair pathways, and a molecular-targeting therapy for the survival pathway Akt-mTOR.

\section{The p53 signaling pathway is activated by various} cellular stresses

The p53 protein was identified in simian virus 40 (SV40) transformed cells where it is associated with the large T antigen (14), 
and was initially considered to be an oncogene. Subsequently, the $p 53$ gene was revealed to be mutated in various human tumors (15), while its protein product was reported to act as a tumor suppressor (16). p53-deleted and $p 53$-mutated cells make up approximately $50 \%$ of the cells in advanced cancers (17).

p53 is normally in 'standby' mode. The p53 protein is a powerful transcription factor and plays a pivotal role in the pathway controlling apoptosis, cell growth and cell proliferation in response to cellular stresses. These include genotoxic and non-genotoxic stresses, such as DNA damage, hypoxia, oncogene overexpression and viral infection (18-20).

The p21/WAF1 (wtp53 activated fragment 1) gene product, a p53 target gene, inactivates the proliferating cell nuclear antigen (PCNA), which can regulate DNA replication (21), and induce a $p 53$-dependent G1 arrest through the inhibition of cyclin/ CDK activity $(22,23)$. During cell cycle arrest, $p 53$-regulated pathways, including those involving growth arrest and DNA damage inducible 45 (Gadd45) and the p53 ribonucleotide reductase small subunit 2 ( $p 53 R 2$ ), are significant in the repair of damaged DNA $(24,25)$. In the absence of competent repair activity, DNA damage induces apoptosis through interactions with other genes in $p 53$-regulated pathways, including the $\mathrm{Bcl}-2$ associated X protein (Bax) (26), p53-upregulated modulator of apoptosis (PUMA) (27), Fas/APO-1 (28) and p53-activated gene 608 (PAG608) (29). By contrast, the $p 53$-regulated MDM2 (murine double minute 2) (30) functions to produce negative feedback, which regulates p53 activity (26).

In the presence of cellular stresses, p53 is subjected to a complex and diverse array of covalent post-translational modifications. These include phosphorylation (31), acetylation (32), poly(ADP-ribosyl)ation (33), ubiquitylation and sumoylation $(34,35)$. In response to cellular stress, Ser15/Ser20 in p53 are phosphorylated and MDM2 is separated from the phosphorylated $\mathrm{p} 53$, leading to the stabilization and activation of p53 (36-38). Therefore, p53 can bind to the promoter of the $p 21$ or $p 53 R 2$ genes associated with DNA repair, and induce their expression. However, if there are numerous DNA lesions or too much cellular damage, G1 arrest and DNA repair will not be successful. In this situation, p53 can be phosphorylated at Ser46, and bind to the promoter of the p53-regulated apoptosis-inducing protein 1 ( $p 53 A I P 1)$ gene, leading to apoptosis $(39,40)$. Moreover, PUMA is reported to be required not only for p53-dependent apoptosis induced by DNA damage, hypoxia and oncogenes, but also for apoptosis induced by p53-independent stimuli, including serum withdrawal, glucocorticoids, kinase inhibitors and phorbol esters (27). By contrast, p53 molecules are inactivated and degraded by activated MDM2 molecules, which are phosphorylated at multiple sites by other protein kinases. In addition, p53 is reported to bind to other proteins, including heat shock proteins (HSPs), functioning as stress proteins $(41,42)$, and Bcl-X (43). Consequently, these modifications of p53 molecules can regulate or affect the fate of cells following exposure to stresses, including cancer therapies.

\section{3. p53-dependent cancer therapy via the restoration of p53 function}

Recently, Poeta et al reported an association between a $p 53$ mutation in a patient with HNSCC and survival following surgical treatment (2). The results demonstrated that p53-deleted and p53-mutated HNSCC patients were significantly associated with short survival periods. These data indicate that p53 mutations could be a useful evaluation or stratification factor in prospective clinical trials. However, in the study, chemotherapy was administered only as an adjuvant measure in combination with postoperative radiation therapy, or prior to study entry in a few cases. There are no data on tumor response to chemotherapy. It would be clinically useful to determine whether $p 53$ mutations are associated with a response to treatments that attack p53-specific pathways. A study described that sensitization to radiation, heat and chemical therapies was observed in cells containing wt $p 53$, but not in cells containing mutated $p 53(\mathrm{~m} p 53)$ in vitro and in vivo (8-10). Furthermore, in attempts to treat cancer using more than one treatment modality, a synergistic depression of tumor growth was found only in tumors containing wtp53 (44). These findings suggest that hyperthermic enhancement of tumor growth inhibition with irradiation may result in $p 53$-dependent apoptosis via caspase-3 activation in HNSCC cells. Therefore, an analysis of $p 53$-gene status in cancer cells could be considered as a useful predictive assay for estimating the possible effectiveness of combined therapies involving radiation, heat and anti-cancer agents. Thus, it is very reasonable to enhance p53-dependent apoptosis pathways through the restoration of p53 function even for mp53 HNSCC cells as a more effective therapeutic strategy. A number of approaches have been employed to achieve this outcome (illustrated in Fig. 1).

A p53 gene therapy-based approach. As previously mentioned, the activation of endogenous $w t p 53$ by radiation and/or chemotherapy in wt $p 53$ cancer cells leads to $p 53$-mediated apoptosis. In recent years, the introduction of exogenous wt $p 53$ into cancer cells, either by gene delivery or by direct protein delivery, has been explored. Although preliminary studies in cell cultures and in animal models have indicated the effectiveness and the low toxicity of these approaches (45-47), their efficacy in clinical trials is currently controversial. Clinical studies in lung, bladder, ovarian and breast cancer revealed the absence of additional beneficial effects compared to conventional treatments (48). On the other hand, encouraging results were reported for phase II and III clinical trials on 135 patients with advanced HNSCC. In this study, patients were treated with a combination of recombinant adenovirus-p53 (Gendicine) administration and radiotherapy. The results demonstrated that $64 \%$ of the patients achieved complete regression, and $32 \%$ achieved partial regression. No serious side effects were observed (49). Although such results are encouraging, further improvements in methods are required to accomplish the safe and effective delivery of wtp53 in vivo (50).

Onyx-015, an adenovirus based therapy. In the absence of wtp53 activity in cancer cells, the generation of a mutated viral vector for tumor cell lysis (Onyx-015) was exploited. McCormick et al from Onyx Pharmaceuticals hypothesized that an adenovirus with the $E 1 B$ region deleted could only replicate and generate cellular lysis in cells lacking functional $\mathrm{p} 53$, due to the putative requirement for $\mathrm{p} 53$ inactivation for adenoviral replication. Accordingly, the Onyx-015 reagent, a p53-targeting oncolytic mutant adenovirus, has been 


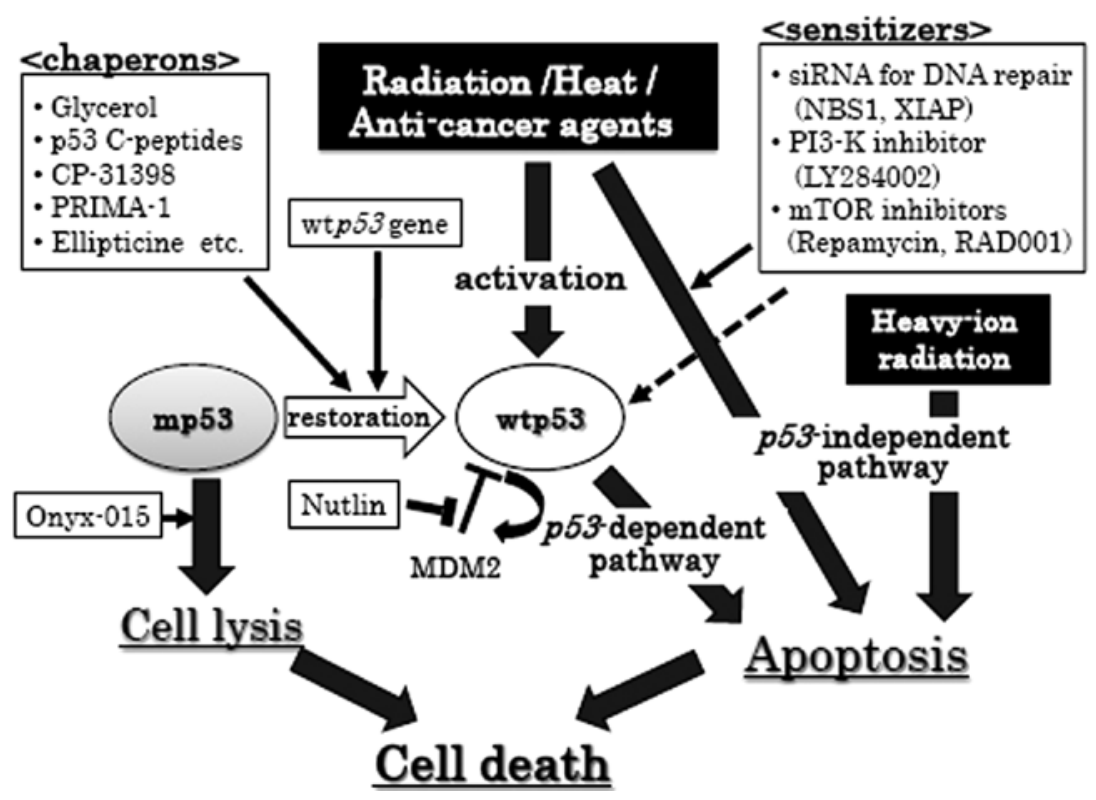

Figure 1. p53-dependent and -independent therapeutic strategies for cancer cells. Circles, $p 53$ status of cancer cells; black squares, cancer therapeutic tool; white squares, enhancer for cancer therapeutic tool; thin arrows, enhancement; dashed arrows, partial enhancement; thick arrows, therapeutic pathway. MDM2, murine double minute 2; XIAP, X-chromosome-linked inhibitor of apoptosis protein; wt 553 , wildtype p53; mp53, mutant p53; siRNA, small interference RNA.

developed for clinical application (51). However, evaluation of numerous clinical trials performed thus far have indicated that the administration of Onyx-015 as a single agent produces only a marginal benefit, whereas its administration in combination with conventional therapy is more effective (52).

\section{Chaperones for the restoration of the p53 molecule}

Glycerol. Another approach in preclinical development involves restoring tumor-suppressing function to $\mathrm{mp53}$. Studies have demonstrated that glycerol, as a chemical chaperone, can restore normal p53 function in mp53 HNSCC cells (53). Glycerol has been previously reported to act as a chemical chaperone due to its ability to refold proteins and restore normal activity; this type of activity was able to alter or restore a functional protein conformation from conformation forms found in a human disease state $(54,55)$. Consistent with this observation, glycerol is capable of restoring p53-dependent radiosensitivity in mp53-HNSCC cells via Bax-mediated induction of apoptosis $(53,56,57)$. Glycerol can also restore heat-induced p53-dependent apoptosis in A-172/mp53 cells (58) and CDDP-induced tumor growth inhibition in $8305 \mathrm{c}$ (59) and SAS/mp53 cells (13), by binding to $\mathrm{p} 53$ consensus sequences ( $553 \mathrm{CON}$ ) located upstream of p53-regulated genes. These results suggest that glycerol could be effective in causing conformational changes that restore wtp53 functioning to mp53, leading to enhanced results with radio-, hyperthermic- and/or chemo-therapies through the induction of apoptosis via a restored wtp53 function.

p53 C-terminal peptides. One of the significant features of p53 tumor-suppressor activity is its ability to bind to p53CON; the majority of mutations in $p 53$ are localized in the binding domain of p53CON $(60,61)$. This sequence-specific DNA-binding ability of p53 is allosterically regulated by its C-terminal domain $(62,63)$, and can be activated in vitro by C-terminal truncation or anti-p53 monoclonal antibody PAb421 binding, which recognizes a C-terminal epitope (64). In addition, small peptides corresponding to the C-terminal residues 369-383 of p53 are capable of activating latent p53, and permit specific DNA-binding in vitro (65). Thus, the sequence-specific DNA binding activity of mp53 proteins could be rescued by PAb421 $(62,66,67)$. The inhibition of cell proliferation (68) and the induction of apoptosis (69) were effectively induced in mp53 cancer cells transfected with $\mathrm{C}$-terminal peptides following X-ray-irradiation or heat-treatment $(70,71)$.

CP-31398 and other small molecules. In other studies evaluating binding to p53CON sequences, CP-31398 was identified as a small molecule with the ability to restore the wild-type conformation to mp53 protein by stabilizing the active conformation of the DNA binding domain $(72,73)$. Further studies have confirmed that CP-31398 treatment causes: i) stabilization of wtp53 levels; ii) apoptosis-related changes; and iii) induction of p53 target genes. Moreover, CP-31398 was demonstrated to increase the levels of wtp53 protein by inhibiting the MDM2-mediated ubiquitylation and degradation of p53 (73). The observation that CP-31398 stabilizes wtp53 suggests that CP-31398 interacts with newly synthesized p53 molecules in vivo and changes its folding behavior (74). Subsequently, PRIMA-1 (75) and ellipticine (76) were also found to be capable of inducing mp53-dependent cell death. On the other hand, Nutlin was developed to rescue wt $p 53$ from degradation mediated by MDM2 (77). More recently, p53 family members could be activated, were capable of serving as substitutes for p53 in tumor cells, and were able to induce cell death. These observations may provide a novel tool for the correction of mp53 conformation and loss of function, and may be applicable to p53-targeted cancer therapy. 


\section{4. p53-independent cancer therapy}

High-LET heavy-ion radiation. High-LET charged particle radiation has several potential advantages over $\mathrm{X}$-rays, including an excellent dose distribution, a higher relative biological effectiveness (RBE), a reduction in the oxygen enhancement ratio, less variation in cell cycle-related radiosensitivity, and the existence of less efficient repair mechanisms for cellular radiation injury (78-80). As a result, high-LET charged particle radiation could have serious lethal effects, even on radioresistant tumors (81). Heavy ion beams can also allow a high radiation dose to be delivered to a tumor with minimal irradiation of the surrounding normal tissues. High-LET radiation also induces apoptosis effectively regardless of the genetic status of the $p 53$ gene in cancer cells $(82,83)$. Heavy ion radiotherapies consequently appear to be attractive for use in numerous types of human cancer. The lack of a $p 53$-regulated pathway is a common feature in a large number of tumors, suggesting that it is a significant factor in the pathogenesis of human cancers. As previously reported, cellular sensitivity to radiation and/or heat depends on the $p 53$-gene status in HNSCC cells $(9,18)$ and other cells $(82,84)$. Therefore, the aim of a number of studies has been to induce apoptosis by reinstating normal functioning of the $\mathrm{m} p 53$ gene (58). However, it has not been practical in the clinic to monitor the status of the $p 53$ gene or other useful genetic markers. Thus, attention has been given to therapies using high-LET radiation, which have highly lethal effects on radioresistant tumors (81), and which can induce apoptosis effectively regardless of the $p 53$-gene status $(82,83)$. It has been suggested that high-LET radiation delivered to HNSCC cells may enhance apoptosis through the activation of caspase- 3 through caspase- 9 , even in the presence of $\mathrm{mp} 53$ (85).

RNA-silencing therapy targeting DNA repair pathway. RNA interference has become a valuable tool for the selective suppression of the expression of a target gene. The mRNAs produced by a targeted gene are cleaved by an RNA-induced silencing complex, which includes small interference RNAs (siRNAs) and a nuclease. Cell cycle signaling or DNA repair proteins, including ATM, ATR and DNA-PKcs, have become the targets of interest in investigations involving the siRNA-mediated enhancement of radiation sensitivity $(86,87)$. Studies have demonstrated the potential use of siRNA as a novel radiation sensitizer for improving the effectiveness of radiation therapy in cancer.

The NBS1 protein is essential for the initial processing of the DNA double-strand break via the homologous recombination (HR) repair pathway $(88,89)$. NBS1 forms a complex with MRE11 and RAD50 in the nucleus. This complex binds to ATM-phosphorylated $\gamma \mathrm{H} 2 \mathrm{AX}$ and is recruited to the area surrounding damaged DNA ends (90). MRE11/RAD50/NBS1 complexes can be visualized in the form of foci in an irradiated area of the nucleus (91). Studies indicate that NBS1 appears to regulate radiation sensitivity in cells through its role in the HR repair system. In addition, it has recently been demonstrated that the siRNA-mediated reduction of NBS1 appears to lead to an increase in radiation-induced mutagenesis in human cells (92).

Ionizing radiation induces a signaling pathway which activates the transcription factor NF- $\mathrm{KB}$. NF- $\mathrm{\kappa B}$ then regulates the transcriptional activation of a number of genes involved in cell proliferation, angiogenesis, metastasis and the suppression of apoptosis (93). Therefore, the radiation-induced activation of NF- $\kappa \mathrm{B}$ could promote oncogenesis and resistance to cancer therapy $(94,95)$. Moreover, it is possible that the NBS1 protein may play a role in the NF- $\kappa \mathrm{B}$ pathway, which is activated by radiation; NBS1-deficient cells exhibit a defective activation of NF- $\kappa B$ following exposure to radiation (96). Thus, inhibition of NBS1 could result in depression of NF- $\kappa B$ activation and in the transcriptional activation of NF- $\kappa \mathrm{B}$-regulated genes. One of the proteins regulated by NF- $\mathrm{B}, \mathrm{X}$-chromosome-linked inhibitor of apoptosis protein (XIAP), plays a pivotal role in cancer progression, and is a strong candidate among cancer therapy targets (97).

Sensitization to radiation results from $N B S I$-siRNA mediated suppression of DNA repair functions and X-ray-induced cell survival signaling pathways, which operate through NF- $\mathrm{KB}$ and XIAP (98). NBS1 is also involved in the heat-induced cellular responses to DNA damage, and it has been suggested that $N B S I$-siRNA is a potential candidate for a sensitizer for heat treatments, which could be effective regardless of cellular p53-gene status $(99,100)$. Moreover, siRNA that can target XIAP can lead to an effective enhancement of X-ray-induced apoptosis in human cancer cells with $\mathrm{m} p 53(98,101)$. The results described in these studies suggest that siRNA designed to target DNA repair functions could lead to novel methods that could increase radiation and/or heat sensitivity, even in human mp53-bearing cancer cells.

Molecular-targeting therapy for Akt-mTOR pathway. The $\mathrm{PI} 3 \mathrm{~K} / \mathrm{Akt}$ pathway is a major cell survival pathway and plays a critical role in oncogenesis and tumor cell growth (102). Recent studies have reported that Akt activation contributes to resistance to radiation, chemotherapy and tyrosine kinase inhibitors by promoting survival signals, which protect cancer cells from undergoing apoptosis $(103,104)$. The inhibition of PI3K/Akt through pharmacological or genetic means induces anti-proliferative effects in HNSCC cells in vitro and in vivo $(105,106)$. Akt is activated by heat and radiation through a phosphatidylinositol-3-kinase (PI3K)-mediated phosphorylation pathway (107). Radio-sensitization induced by LY294002, a specific inhibitor of PI3K, has been reported in in vitro (108) and in vivo experiments (109). LY294002 inhibits anti-apoptosis signaling through the induction of Hsp27 and Hsp72, and cell survival signaling through Akt and survivin. LY294002 appears to be a noteworthy candidate as a $p 53$-independent heat sensitizer in hyperthermic cancer therapy (110).

The mammalian target of rapamycin, mTOR, is a $289-\mathrm{kDa}$ serine-threonine kinase, which acts as a downstream effector for Akt (111). It regulates key processes, including cell growth and proliferation, cell cycle progression and protein translation through two distinct pathways; one involving the ribosomal p70S6 kinase (p70S6K), and one involving the eukaryotic translation initiation factor 4E (eIF4E) binding proteins (4E-BPs) (112). Akt activation is closely associated with the upregulation of mTOR activity. It has been suggested that dysregulation of mTOR contributes to cancer progression (111), and therefore, mTOR may be a potential therapeutic target which could inhibit or block the PI3K/Akt pathway. Inhibitors 
of mTOR are currently under development; rapamycin and its derivatives CCI-770, AP23573 and RAD001. The antiproliferative effects of mTOR inhibitors have been observed in various tumor cells in vitro and in vivo (113-115). These mTOR inhibitors are generally regarded as cytostatic agents, since they induce G1 cell cycle arrest, but not apoptosis (113). However, recent studies have demonstrated that mTOR inhibitors can enhance the cytotoxic effects of chemotherapeutic agents and radiation in a number of human cancers (116-118). Furthermore, a study has demonstrated that rapamycin in combination with radiation was able to augment the cytostatic effects of radiation regardless of cellular $p 53$-gene status in lung cancer and HNSCC cells, suggesting that inhibition of the mTOR signaling may be a promising strategy for radiosensitization regardless of $p 53$-gene status, with respect to cell lethality and cell growth depression (119).

\section{Conclusion}

Over the past few decades, despite the introduction of new multimodal therapies, there has been a failure to achieve a high efficacy in tumor therapy. This may be caused by a primary or acquired resistance to the DNA damaging agents used in chemotherapy and radiotherapy, and remains a formidable and poorly understood problem. This review discussed the effect of p53-targeting cancer therapies on p53 signaling pathways, including p53-gene therapy, chemical chaperones, p53 C-terminal peptides, p53-targeting chemicals and inhibitors targeting several signaling pathways, in an effort to induce cell death in cancer cells. High-LET radiation can induce apoptosis effectively regardless of the genetic status of the p53-gene in cancer cells. Identification of the p53 status in the target cells is imperative, and the knowledge of additional oncogenic events contributing to specific types of cancer could significantly aid in the selection of appropriate therapeutic protocols. The restoration of p53 functioning could be helpful when pathways upstream of p53 expression are defective, but not if defects are downstream of p53 signaling. The re-expression and re-activation of p53 in human cancer cells could increase tumor susceptibility to radiation or chemotherapy, enhance the efficacy of standard therapeutic protocols, and lead to individually designed therapies (52). Further investigations in this area will hopefully lead to more effective cancer treatments in the near future.

\section{Acknowledgements}

This work was supported in part by Grants-in-Aid for Scientific Research from the Ministry of Education, Culture, Sports, Science and Technology of Japan.

\section{References}

1. Jemal A, Siegel R, Xu J and Ward E: Cancer statistics, 2010. CA Cancer J Clin 60: 277-300.

2. Poeta ML, Manola J, Goldwasser MA, et al: TP53 mutations and survival in squamous-cell carcinoma of the head and neck. N Engl J Med 357: 2552-2561, 2007.

3. Vogelstein B, Lane D and Levine AJ: Surfing the p53 network. Nature 408: 307-310, 2000.

4. Guimaraes DP and Hainaut P: TP53: a key gene in human cancer. Biochimie 84: 83-93, 2002.
5. Gasco $\mathrm{M}$ and Crook T: The p53 network in head and neck cancer. Oral Oncol 39: 222-231, 2003.

6. Lowe SW: Cancer therapy and p53. Curr Opin Oncol 7: 547-553, 1995.

7. Velculescu VE and El-Deiry WS: Biological and clinical importance of the p53 tumor suppressor gene. Clin Chem 42: 858-868, 1996.

8. Ota I, Ohnishi K, Takahashi A, et al: Transfection with mutant p53 gene inhibits heat-induced apoptosis in a head and neck cell line of human squamous cell carcinoma. Int J Radiat Oncol Biol Phys 47: 495-501, 2000.

9. Takahashi A: Different inducibility of radiation- or heat-induced p53-dependent apoptosis after acute or chronic irradiation in human cultured squamous cell carcinoma cells. Int J Radiat Biol 77: 215-224, 2001.

10. Ohnishi K, Ota I, Takahashi A, Yane K, Matsumoto H and Ohnishi T: Transfection of mutant p53 gene depresses X-ray- or CDDP-induced apoptosis in a human squamous cell carcinoma of the head and neck. Apoptosis 7: 367-372, 2002.

11. Asakawa I, Yoshimura H, Takahashi A, et al: Radiation-induced growth inhibition in transplanted human tongue carcinomas with different p53 gene status. Anticancer Res 22: 2037-2043, 2002.

12. Tamamoto T, Yoshimura H, Takahashi A, et al: Heat-induced growth inhibition and apoptosis in transplanted human head and neck squamous cell carcinomas with different status of p53. Int J Hyperthermia 19: 590-597, 2003.

13. Yuki K, Takahashi A, Ota I, et al: Sensitization by glycerol for CDDP-therapy against human cultured cancer cells and tumors bearing mutated p53 gene. Apoptosis 9: 853-859, 2004.

14. Lane DP and Crawford LV: T antigen is bound to a host protein in SV40-transformed cells. Nature 278: 261-263, 1979.

15. Nigro JM, Baker SJ, Preisinger AC, et al: Mutations in the p53 gene occur in diverse human tumour types. Nature 342: 705-708, 1989.

16. Finlay CA, Hinds PW and Levine AJ: The p53 proto-oncogene can act as a suppressor of transformation. Cell 57: 1083-1093, 1989.

17. Hollstein M, Sidransky D, Vogelstein B and Harris CC: p53 mutations in human cancers. Science 253: 49-53, 1991.

18. Efeyan A and Serrano M: p53: guardian of the genome and policeman of the oncogenes. Cell Cycle 6: 1006-1010, 2007.

19. Slee EA, O'Connor DJ and Lu X: To die or not to die: how does p53 decide? Oncogene 23: 2809-2818, 2004.

20. Vousden KH and Lu X: Live or let die: the cell's response to p53. Nat Rev Cancer 2: 594-604, 2002.

21. Bambara RA and Jessee CB: Properties of DNA polymerases delta and epsilon, and their roles in eukaryotic DNA replication. Biochim Biophys Acta 1088: 11-24, 1991.

22. El-Deiry WS, Tokino T, Velculescu VE, et al: WAF1, a potential mediator of p53 tumor suppression. Cell 75: 817-825, 1993.

23. Deng C, Zhang P, Harper JW, Elledge SJ and Leder P: Mice lacking p21CIP1/WAF1 undergo normal development, but are defective in G1 checkpoint control. Cell 82: 675-684, 1995.

24. Kastan MB, Zhan Q, el-Deiry WS, et al: A mammalian cell cycle checkpoint pathway utilizing p53 and GADD45 is defective in ataxia-telangiectasia. Cell 71: 587-597, 1992.

25. Smith ML, Kontny HU, Zhan Q, Sreenath A, O'Connor PM and Fornace AJ Jr: Antisense GADD45 expression results in decreased DNA repair and sensitizes cells to u.v.-irradiation or cisplatin. Oncogene 13: 2255-2263, 1996.

26. Miyashita T and Reed JC: Tumor suppressor p53 is a direct transcriptional activator of the human bax gene. Cell 80: 293-299, 1995.

27. Yu J and Zhang L: No PUMA, no death: implications for p53-dependent apoptosis. Cancer Cell 4: 248-249, 2003.

28. Owen-Schaub LB, Zhang W, Cusack JC, et al: Wild-type human p53 and a temperature-sensitive mutant induce Fas/APO-1 expression. Mol Cell Biol 15: 3032-3040, 1995.

29. Israeli D, Tessler E, Haupt Y, et al: A novel p53-inducible gene, PAG608, encodes a nuclear zinc finger protein whose overexpression promotes apoptosis. EMBO J 16: 4384-4392, 1997.

30. Haupt S, Louria-Hayon I and Haupt Y: P53 licensed to kill? Operating the assassin. J Cell Biochem 88: 76-82, 2003.

31. Barak Y and Oren M: Enhanced binding of a $95 \mathrm{kDa}$ protein to p53 in cells undergoing p53-mediated growth arrest. EMBO J 11: 2115-2121, 1992.

32. Brooks CL and Gu W: Ubiquitination, phosphorylation and acetylation: the molecular basis for p53 regulation. Curr Opin Cell Biol 15: 164-171, 2003. 
33. Valenzuela MT, Guerrero R, Nunez MI, et al: PARP-1 modifies the effectiveness of p53-mediated DNA damage response. Oncogene 21: 1108-1116, 2002.

34. Schmidt D and Muller S: Members of the PIAS family act as SUMO ligases for c-Jun and p53 and repress p53 activity. Proc Natl Acad Sci USA 99: 2872-2877, 2002.

35. Melchior F and Hengst L: SUMO-1 and p53. Cell Cycle 1: 245-249, 2002

36. Siliciano JD, Canman CE, Taya Y, Sakaguchi K, Appella E and Kastan MB: DNA damage induces phosphorylation of the amino terminus of p53. Genes Dev 11: 3471-3481, 1997.

37. Shieh SY, Ahn J, Tamai K, Taya Y and Prives C: The human homologs of checkpoint kinases Chk1 and Cds1 (Chk2) phosphorylate p53 at multiple DNA damage-inducible sites. Genes Dev 14: 289-300, 2000

38. Urban G, Golden T, Aragon IV, et al: Identification of a functional link for the p53 tumor suppressor protein in dexamethasoneinduced growth suppression. J Biol Chem 278: 9747-9753, 2003.

39. Oda K, Arakawa H, Tanaka T, et al: p53AIP1, a potential mediator of p53-dependent apoptosis, and its regulation by Ser-46-phosphorylated p53. Cell 102: 849-862, 2000.

40. Saito S, Goodarzi AA, Higashimoto Y, et al: ATM mediates phosphorylation at multiple p53 sites, including $\operatorname{Ser}(46)$, in response to ionizing radiation. J Biol Chem 277: 12491-12494, 2002.

41. Ohnishi T, Matsumoto $H$, Takahashi A, Shimura $M$ and Majima HJ: Accumulation of mutant p53 and hsp72 by heat treatment, and their association in a human glioblastoma cell line. Int J Hyperthermia 11: 663-671, 1995.

42. Matsumoto $H$, Wang $X$ and Ohnishi $T$ : Binding between wild-type p53 and hsp72 accumulated after UV and gamma-ray irradiation. Cancer Lett 92: 127-133, 1995.

43. Petros AM, Gunasekera A, Xu N, Olejniczak ET and Fesik SW: Defining the p53 DNA-binding domain/Bcl-x(L)-binding interface using NMR. FEBS Lett 559: 171-174, 2004.

44. Takahashi A, Ota I, Tamamoto T, et al: p53-dependent hyperthermic enhancement of tumour growth inhibition by X-ray or carbon-ion beam irradiation. Int J Hyperthermia 19: 145-153, 2003.

45. Fujiwara T, Cai DW, Georges RN, Mukhopadhyay T, Grimm EA and Roth JA: Therapeutic effect of a retroviral wild-type p53 expression vector in an orthotopic lung cancer model. J Natl Cancer Inst 86: 1458-1462, 1994

46. Scardigli R, Bossi G, Blandino G, Crescenzi M, Soddu S and Sacchi A: Expression of exogenous wt-p53 does not affect normal hematopoiesis: implications for bone marrow purging. Gene Ther 4: 1371-1378, 1997.

47. Bossi G, Mazzaro G, Porrello A, Crescenzi M, Soddu S and Sacchi A: Wild-type p53 gene transfer is not detrimental to normal cells in vivo: implications for tumor gene therapy. Oncogene 23: 418-425, 2004

48. Vecil GG and Lang FF: Clinical trials of adenoviruses in brain tumors: a review of Ad-p53 and oncolytic adenoviruses. J Neurooncol 65: 237-246, 2003.

49. Pearson S, Jia H and Kandachi K: China approves first gene therapy. Nat Biotechnol 22: 3-4, 2004.

50. Bossi G, Lapi E, Strano S, Rinaldo C, Blandino G and Sacchi A Mutant p53 gain of function: reduction of tumor malignancy of human cancer cell lines through abrogation of mutant p53 expression. Oncogene 25: 304-309, 2006.

51. Bischoff JR, Kirn DH, Williams A, et al: An adenovirus mutant that replicates selectively in p53-deficient human tumor cells. Science 274: 373-376, 1996.

52. Bossi G and Sacchi A: Restoration of wild-type p53 function in human cancer: relevance for tumor therapy. Head Neck 29: 272-284, 2007.

53. Ohnishi K, Ota I, Takahashi A and Ohnishi T: Glycerol restores p53-dependent radiosensitivity of human head and neck cance cells bearing mutant p53. Br J Cancer 83: 1735-1739, 2000.

54. Welch WJ and Brown CR: Influence of molecular and chemical chaperones on protein folding. Cell Stress Chaperones 1: 109-115, 1996.

55. Thomas PJ, Qu BH and Pedersen PL: Defective protein folding as a basis of human disease. Trends Biochem Sci 20: 456-459, 1995.

56. Ohnishi K, Ota I, Yane K, et al: Glycerol as a chemical chaperone enhances radiation-induced apoptosis in anaplastic thyroid carcinoma cells. Mol Cancer 1: 4, 2002.

57. Imai Y, Ohnishi K, Yasumoto J, et al: Glycerol enhances radiosensitivity in a human oral squamous cell carcinoma cell line (Ca9-22) bearing a mutant $\mathrm{p} 53$ gene via Bax-mediated induction of apoptosis. Oral Oncol 41: 631-636, 2005.
58. Ohnishi T, Ohnishi K and Takahashi A: Glycerol restores heat-induced p53-dependent apoptosis of human glioblastoma cells bearing mutant p53. BMC Biotechnol 2: 6, 2002.

59. Yuki K, Takahashi A, Ota I, et al: Glycerol enhances CDDP-induced growth inhibition of thyroid anaplastic carcinoma tumor carrying mutated p53 gene. Oncol Rep 11: 821-824, 2004

60. Bargonetti J, Friedman PN, Kern SE, Vogelstein B and Prives C: Wild-type but not mutant $\mathrm{p} 53$ immunopurified proteins bind to sequences adjacent to the SV40 origin of replication. Cell 65: 1083-1091, 1991

61. Cho Y, Gorina S, Jeffrey PD and Pavletich NP: Crystal structure of a p53 tumor suppressor-DNA complex: understanding tumorigenic mutations. Science 265: 346-355, 1994.

62. Halazonetis TD and Kandil AN: Conformational shifts propagate from the oligomerization domain of p53 to its tetrameric DNA binding domain and restore DNA binding to select p53 mutants. EMBO J 12: 5057-5064, 1993.

63. Hupp TR, Meek DW, Midgley CA and Lane DP: Regulation of the specific DNA binding function of p53. Cell 71: 875-886, 1992.

64. Hupp TR and Lane DP: Allosteric activation of latent p53 tetramers. Curr Biol 4: 865-875, 1994.

65. Hupp TR, Sparks A and Lane DP: Small peptides activate the latent sequence-specific DNA binding function of p53. Cell 83: 237-245, 1995.

66. Hupp TR, Meek DW, Midgley CA and Lane DP: Activation of the cryptic DNA binding function of mutant forms of $\mathrm{p} 53$. Nucleic Acids Res 21: 3167-3174, 1993.

67. Abarzua P, LoSardo JE, Gubler ML, et al: Restoration of the transcription activation function to mutant p53 in human cancer cells. Oncogene 13: 2477-2482, 1996.

68. Selivanova G, Iotsova V, Okan I, et al: Restoration of the growth suppression function of mutant $\mathrm{p} 53$ by a synthetic peptide derived from the p53 C-terminal domain. Nat Med 3: 632-638, 1997.

69. Kim AL, Raffo AJ, Brandt-Rauf PW, et al: Conformational and molecular basis for induction of apoptosis by a p53 C-terminal peptide in human cancer cells. J Biol Chem 274: 34924-34931, 1999.

70. Ohnishi K, Inaba H, Yasumoto J, Yuki K, Takahashi A and Ohnishi T: C-terminal peptides of p53 molecules enhance radiation-induced apoptosis in human mutant p53 cancer cells. Apoptosis 9: 591-597, 2004

71. Selivanova G, Ryabchenko L, Jansson E, Iotsova V and Wiman KG: Reactivation of mutant p53 through interaction of a C-terminal peptide with the core domain. Mol Cell Biol 19: 3395-3402, 1999.

72. Foster BA, Coffey HA, Morin MJ and Rastinejad F: Pharmacological rescue of mutant p53 conformation and function. Science 286: 2507-2510, 1999.

73. Takimoto R, Wang W, Dicker DT, Rastinejad F, Lyssikatos J and el-Deiry WS: The mutant p53-conformation modifying drug, CP-31398, can induce apoptosis of human cancer cells and can stabilize wild-type p53 protein. Cancer Biol Ther 1: 47-55, 2002.

74. Rippin TM, Bykov VJ, Freund SM, Selivanova G, Wiman KG and Fersht AR: Characterization of the p53-rescue drug CP-31398 in vitro and in living cells. Oncogene 21: 2119-2129, 2002.

75. Bykov VJ, Issaeva N, Shilov A, et al: Restoration of the tumor suppressor function to mutant p53 by a low-molecular-weight compound. Nat Med 8: 282-288, 2002.

76. Peng Y, Li C, Chen L, Sebti S and Chen J: Rescue of mutant p53 transcription function by ellipticine. Oncogene 22: 4478-4487, 2003.

77. Vassilev LT, Vu BT, Graves B, et al: In vivo activation of the p53 pathway by small-molecule antagonists of MDM2. Science 303: 844-848, 2004

78. Blakely EA and Kronenberg A: Heavy-ion radiobiology: new approaches to delineate mechanisms underlying enhanced biological effectiveness. Radiat Res 150: S126-S145, 1998.

79. Guida P, Vazquez ME and Otto S: Cytotoxic effects of lowand high-LET radiation on human neuronal progenitor cells: induction of apoptosis and TP53 gene expression. Radiat Res 164: $545-551,2005$.

80. Demizu Y, Kagawa K, Ejima Y, et al: Cell biological basis for combination radiotherapy using heavy-ion beams and highenergy X-rays. Radiother Oncol 71: 207-211, 2004.

81. Debus J, Jackel O, Kraft G and Wannenmacher M: Is there a role for heavy ion beam therapy? Recent Results Cancer Res 150: 170-182, 1998.

82. Takahashi A, Matsumoto H, Yuki K, et al: High-LET radiation enhanced apoptosis but not necrosis regardless of p53 status. Int J Radiat Oncol Biol Phys 60: 591-597, 2004. 
83. Takahashi A, Matsumoto H, Furusawa Y, Ohnishi K, Ishioka N and Ohnishi T: Apoptosis induced by high-LET radiations is not affected by cellular p53 gene status. Int J Radiat Biol 81: 581-586, 2005.

84. Takahashi A, Ohnishi K, Wang X, et al: The dependence of $\mathrm{p} 53$ on the radiation enhancement of thermosensitivity at different LET. Int J Radiat Oncol Biol Phys 47: 489-494, 2000.

85. Yamakawa N, Takahashi A, Mori E, et al: High LET radiation enhances apoptosis in mutated p53 cancer cells through caspase-9 activation. Cancer Sci 99: 1455-1460, 2008.

86. Peng Y, Zhang Q, Nagasawa H, Okayasu R, Liber HL and Bedford JS: Silencing expression of the catalytic subunit of DNA-dependent protein kinase by small interfering RNA sensitizes human cells for radiation-induced chromosome damage, cell killing, and mutation. Cancer Res 62: 6400-6404, 2002.

87. Collis SJ, Swartz MJ, Nelson WG and DeWeese TL: Enhanced radiation and chemotherapy-mediated cell killing of human cancer cells by small inhibitory RNA silencing of DNA repair factors. Cancer Res 63: 1550-1554, 2003.

88. Tauchi H, Kobayashi J, Morishima K, et al: Nbs1 is essential for DNA repair by homologous recombination in higher vertebrate cells. Nature 420: 93-98, 2002

89. Sakamoto S, Iijima K, Mochizuki D, et al: Homologous recombination repair is regulated by domains at the $\mathrm{N}$ - and $\mathrm{C}$-terminus of NBS1 and is dissociated with ATM functions. Oncogene 26: 6002-6009, 2007.

90. Tauchi H, Matsuura S, Kobayashi J, Sakamoto S and Komatsu K: Nijmegen breakage syndrome gene, NBS1, and molecular links to factors for genome stability. Oncogene 21: 8967-8980, 2002.

91. Nelms BE, Maser RS, MacKay JF, Lagally MG and Petrini JH In situ visualization of DNA double-strand break repair in human fibroblasts. Science 280: 590-592, 1998.

92. Zhang Y, Lim CU, Williams ES, et al: NBS1 knockdown by small interfering RNA increases ionizing radiation mutagenesis and telomere association in human cells. Cancer Res 65: 5544-5553, 2005.

93. Lee SJ, Dimtchev A, Lavin MF, Dritschilo A and Jung M: A novel ionizing radiation-induced signaling pathway that activates the transcription factor NF-kappaB. Oncogene 17: 1821-1826, 1998.

94. Orlowski RZ and Baldwin AS Jr: NF-kappaB as a therapeutic target in cancer. Trends Mol Med 8: 385-389, 2002.

95. Yamagishi N, Miyakoshi J and Takebe H: Enhanced radiosensitivity by inhibition of nuclear factor kappa B activation in human malignant glioma cells. Int J Radiat Biol 72: 157-162, 1997.

96. Habraken Y, Jolois O and Piette J: Differential involvement of the hMRE11/hRAD50/NBS1 complex, BRCA1 and MLH1 in NF-kappaB activation by camptothecin and X-ray. Oncogene 22 6090-6099, 2003

97. LaCasse EC, Baird S, Korneluk RG and MacKenzie AE: The inhibitors of apoptosis (IAPs) and their emerging role in cancer. Oncogene 17: 3247-3259, 1998.

98. Ohnishi K, Scuric Z, Schiestl RH, Okamoto N, Takahashi A and Ohnishi T: siRNA targeting NBS1 or XIAP increases radiation sensitivity of human cancer cells independent of TP53 status. Radiat Res 166: 454-462, 2006.

99. Ohnishi K, Scuric Z, Yau D, et al: Heat-induced phosphorylation of NBS1 in human skin fibroblast cells. J Cell Biochem 99: 1642-1650, 2006.

100. Okamoto N, Takahashi A, Ota I, et al: siRNA targeted for NBS1 enhances heat sensitivity in human anaplastic thyroid carcinoma cells. Int J Hyperthermia 27: 297-304.

101. Ohnishi K, Nagata Y, Takahashi A, Taniguchi S and Ohnishi T: Effective enhancement of X-ray-induced apoptosis in human cancer cells with mutated p53 by siRNA targeting XIAP. Oncol Rep 20: 57-61, 2008.

102. Nicholson KM and Anderson NG: The protein kinase B/Akt signalling pathway in human malignancy. Cell Signal 14: 381-395, 2002 .
103. Vivanco I and Sawyers CL: The phosphatidylinositol 3-kinase AKT pathway in human cancer. Nat Rev Cancer 2: 489-501, 2002.

104. Bjornsti MA and Houghton PJ: The TOR pathway: a target for cancer therapy. Nat Rev Cancer 4: 335-348, 2004

105. Wang F, Arun P, Friedman J, Chen Z and Van Waes C: Current and potential inflammation targeted therapies in head and neck cancer. Curr Opin Pharmacol 9: 389-395, 2009.

106. Raimondi AR, Molinolo A and Gutkind JS: Rapamycin prevents early onset of tumorigenesis in an oral-specific K-ras and p53 two-hit carcinogenesis model. Cancer Res 69: 4159-4166, 2009.

107. Shaw M, Cohen P and Alessi DR: The activation of protein kinase $\mathrm{B}$ by $\mathrm{H}_{2} \mathrm{O}_{2}$ or heat shock is mediated by phosphoinositide 3-kinase and not by mitogen-activated protein kinase-activated protein kinase-2. Biochem J 336: 241-246, 1998.

108. Rosenzweig KE, Youmell MB, Palayoor ST and Price BD: Radiosensitization of human tumor cells by the phosphatidylinositol3-kinase inhibitors wortmannin and LY294002 correlates with inhibition of DNA-dependent protein kinase and prolonged G2-M delay. Clin Cancer Res 3: 1149-1156, 1997.

109. Gupta AK, Cerniglia GJ, Mick R, et al: Radiation sensitization of human cancer cells in vivo by inhibiting the activity of PI3K using LY294002. Int J Radiat Oncol Biol Phys 56: 846-853, 2003 .

110. Ohnishi K, Yasumoto J, Takahashi A and Ohnishi T: LY294002, an inhibitor of PI-3K, enhances heat sensitivity independently of p53 status in human lung cancer cells. Int J Oncol 29: 249-253, 2006.

111. Guertin DA and Sabatini DM: Defining the role of mTOR in cancer. Cancer Cell 12: 9-22, 2007.

112. Hay N and Sonenberg N: Upstream and downstream of mTOR. Genes Dev 18: 1926-1945, 2004

113. Beuvink I, Boulay A, Fumagalli S, et al: The mTOR inhibitor RAD001 sensitizes tumor cells to DNA-damaged induced apoptosis through inhibition of p21 translation. Cell 120: 747-759, 2005.

114. Majumder PK, Febbo PG, Bikoff R, et al: mTOR inhibition reverses Akt-dependent prostate intraepithelial neoplasia through regulation of apoptotic and HIF-1-dependent pathways. Nat Med 10: 594-601, 2004

115. Boulay A, Zumstein-Mecker S, Stephan C, et al: Antitumor efficacy of intermittent treatment schedules with the rapamycin derivative RAD001 correlates with prolonged inactivation of ribosomal protein S6 kinase 1 in peripheral blood mononuclear cells. Cancer Res 64: 252-261, 2004.

116. Mabuchi S, Altomare DA, Cheung M, et al: RAD001 inhibits human ovarian cancer cell proliferation, enhances cisplatininduced apoptosis, and prolongs survival in an ovarian cancer model. Clin Cancer Res 13: 4261-4270, 2007.

117. Cao C, Subhawong T, Albert JM, et al: Inhibition of mammalian target of rapamycin or apoptotic pathway induces autophagy and radiosensitizes PTEN null prostate cancer cells. Cancer Res 66: 10040-10047, 2006

118. Albert JM, Kim KW, Cao C and Lu B: Targeting the $\mathrm{Akt} / \mathrm{mammalian}$ target of rapamycin pathway for radiosensitization of breast cancer. Mol Cancer Ther 5: 1183-1189, 2006.

119. Nagata Y, Takahashi A, Ohnishi K, et al: Effect of rapamycin, an mTOR inhibitor, on radiation sensitivity of lung cancer cells having different p53 gene status. Int J Oncol 37: 1001-1010. 